\title{
Comprehensive Research and Application of Cloud Computing in Enterprises
}

\author{
Tao Feng $^{1}$ and Yun Cheng ${ }^{2}$ \\ Liaoning Economic Vocational Technology Institute, China \\ tailwind@126.com, teachercy@126.com
}

\begin{abstract}
With a crucial development of information and communications technology over the last century, there is an increasingly perceived vision that computing will be the $5^{\text {th }}$ utility in human's civilization. Like all other four existing utilities, this computing utility will provide basic level of computing service which is considered essential to meet everyday needs of the general community. In order to deliver this vision, a number of computing paradigms have been proposed, of which the latest one is known as Cloud computing. Therefore, in this paper, we introduced the definition of Cloud computing and provide the architecture for creating Clouds with market-oriented resource allocation by leveraging technologies. We also provide a hypothetical case analysis to show the economical efficiency for medium-sized enterprise to deploy servers on the cloud instead of establishing server center of their own. Finally, a conclusion is drawn that there is need for convergence of competing IT paradigms to deliver our new century vision and it is economical efficient for medium-sized enterprise to use cloud computing services.
\end{abstract}

Keywords: cloud computing, enterprise, economic efficiency

\section{Introduction}

Computing is being transformed to a model consisting of services that are commoditized and delivered in a manner similar to traditional utilities such as water, electricity, gas, and telephony. Under this pattern, users can obtain services on the basis of their demands without regarding to where the services are hosted or how they are delivered. A series of computing paradigms have abilities to deliver this utility computing vision, including cluster computing, Grid computing, and Cloud computing. The latter term denotes the infrastructure as a "Cloud" from which businesses and people can acquire applications from all over the world. Hence, the computing world is rapidly transforming towards developing software for millions to consume as a service, instead of running on their individual computers.

Nowadays, it is common to obtain content across the Internet all alone without references to the underlying hosting infrastructure, which consists of data centers that are maintained around the clock by content providers. Cloud computing is an extension if this paradigm wherein the abilities of commercial applications are exposed as complex services that can be accessed through a network. Cloud service providers are incentivized by the profits to be made by charging consumers for accessing these services. As to the consumers like companies, they are attracted by the chances for abating or eliminating costs associated with in-house provision of these services. Nevertheless, since cloud applications may be significant to the central business operations of the consumers, it is core that the consumers have guarantees from providers on service delivery. Typically, these are usually provided through Service Level Agreements (SLAs) brokered between the providers and consumers. 
Just as some of the big enterprises, providers have begun to build new data centers for hosting Cloud computing applications in different positions from all over the world, providing redundancy and ensure reliability of the process, eschewing site failures. Since users' requirements for cloud services are quiet different, providers must pledge that they can be flexible in their service delivery while keeping the users separated from underlying infrastructure. Recently, developments in microprocessor technology have led to the increasing capacity of relative hardware to run these "appliances" of Virtual Machines (VMs) availably. VMs can promise the isolation of applications and the customization of the needed platform of users. Providers can provide access and correlative applications to VMs as a service, hence allowing consumers to set up their own applications.

Based on this context, in our study, we aimed at discussing the Cloud computing definitions, and providing a hypothetical case analysis to show the economical efficiency of medium-sized enterprise for the sake of deploying servers on the Cloud instead of establishing server center of their own.

\section{Definition of Cloud Computing}

The existing Cloud definitions based on previous studies provided by relative experts are shown on Table 1. T It's worth mentioning that reference [1] gathers various definitions proposed by many experts. Though it lacks a integral analysis of those proposals to reach a sheer definition, these descriptions offer different explanations about Clouds of diverse aspects.

According to Vaquero's [1] work, several definitions of cloud is gathered as Table 1

Table 1. Cloud Definitions [1]

\begin{tabular}{|l|l|}
\hline Author/Reference & Definition /Excerpt \\
\hline M. Klems [2] & $\begin{array}{l}\text { You can scale your infrastructure on demand within minutes or even } \\
\text { seconds, instead of days or weeks, thereby avoiding under-utilization } \\
\text { (idle servers) and over-utilization (blue screen) of in-house resources... }\end{array}$ \\
\hline P. Gaw [2] & $\begin{array}{l}\text { Using the internet to allow people to access technology-enabled services. } \\
\text { Those services must be 'massively scalable... }\end{array}$ \\
\hline R. Buyya [3] & $\begin{array}{l}\text { A Cloud is a type of parallel and distributed system consisting of a } \\
\text { collection of interconnected and virtualized computers that are } \\
\text { dynamically provisioned and presented as one or more unified } \\
\text { computing resources based on service-level agreements established } \\
\text { through negotiation between the service provider and consumers }\end{array}$ \\
\hline R. Cohen [2] & $\begin{array}{l}\text { Cloud computing is one of those catch all buzz words that tries to } \\
\text { encompass a variety of aspects ranging from deployment, load } \\
\text { balancing, provisioning, business model and architecture (like Web2.0). } \\
\text { It's the next logical step in software (software 10.0). For me the simplest } \\
\text { explanation for Cloud Computing is describing it as, "internet centric } \\
\text { software... }\end{array}$ \\
\hline R. Bragg [4] & $\begin{array}{l}\text { The key concept behind the Cloud is Web application... a more } \\
\text { developed and reliable Cloud. Many find it's now cheaper to migrate to } \\
\text { the Web Cloud than invest in their own server farm ... it is a desktop for } \\
\text { people without a computer. }\end{array}$ \\
\hline $\begin{array}{l}\text { G. Gruman and E. } \\
\text { Knorr [5] }\end{array}$ & $\begin{array}{l}\text { Cloud is all about: SaaS...utility computing...Web Services... } \\
\text { PaaS...Internet integration...commerce platforms.... }\end{array}$ \\
\hline $\begin{array}{l}\text { P. McFedries [6, } \\
\text { 7] }\end{array}$ & $\begin{array}{l}\text { Cloud Computing, in which not just our data but even our software } \\
\text { resides within the Cloud, and we access everything not only through our } \\
\text { PCs but also Cloud-friendly devices, such as smart phones, PDAs... the }\end{array}$ \\
\hline
\end{tabular}


To obtain a sheer understanding of the foundational of Cloud computing, we compared Cloud computing with two other computing paradigms: Cluster Computing and Grid Computing. First of all, the respective definition of these three paradigms was examined, afterword, we differentiated their specific functions.

Plenty of experts and practitioners have tried to define clusters, Grids, and Clouds [2] in different ways. Here are some definitions that we consider are generic enough to stand the test of time.

Pfister's [8] and Buyya's [9] work defines the clusters in a specific way, which is shown as follows:

"A cluster is a type of parallel and distributed system, which consists of a collection of inter-connected stand-alone computers working together as a single integrated computing resource".

Buyya defined one of the popular definitions for Grids at the 2002 Grid Planet conference, San Jose, USA as follows:

"A Grid is a type of parallel and distributed system that enables the sharing, selection, and aggregation of geographically distributed 'autonomous' resources dynamically at runtime depending on their availability, capability, performance, cost, and users' quality-of-service requirements."

On the basis of the understanding of the essence of the Cloud's duty, like most of the relative researchers, we tempted to agree with the following definition proposed by Buyya [10]:

"A cloud is a type of parallel and distributed system consisting of a collection of inter-connected and virtualized computers that are dynamically provisioned and presented as one or more unified computing resource(s) based on service-level agreements established through negotiation between the service provider and consumers."

Generally speaking, Clouds appear to be a conjunction of clusters and Grids. Nevertheless, Clouds are clearly next-generation data centers with nodes "virtualized" via relative applications like VMs, "provisioned" on demand as a personalized resource collection to achieve a specific service-level agreement, which is developed via a "negotiation" and accessible as a compostable service through Web Service applications like REST.

\section{Comparison on Characteristics of Cluster Grid and Cloud Computing}

A set of features, discussed by previous researches [11-16] can help us to differentiate the three systems, including cluster, Grid and Cloud computing systems, which is listed in Table 1. Resources in clusters are located in a single administrative domain and managed by a single entity while resources are geographically distributed across multiple administrative domains with their own management policies and goals in Grid systems. Another conspicuous difference between cluster and Grid systems is how the applications scheduling are applied. The schedulers in cluster systems aim at enhancing the whole system performance when they are responsible for the overall system. On the other hand, the schedulers in Grid systems called resource brokers, aiming at enhancing the performance of practical applications in a way that its end-users' QoS requirements are met.

Cloud computing platforms owns features of both clusters and Grids Hence, Clouds can ensure to provide services to users without reference to the infrastructure on which these are hosted. 
Table 2. Characteristics of Clusters, Grids and Cloud Systems [10]

\begin{tabular}{|c|c|c|c|}
\hline & Clusters & Grids & Clouds \\
\hline Population & $\begin{array}{l}\text { Commodity } \\
\text { computers }\end{array}$ & $\begin{array}{l}\text { High-end computers } \\
\text { (servers, clusters) }\end{array}$ & $\begin{array}{l}\text { Commodity } \\
\text { computers and } \\
\text { high-end servers and } \\
\text { network attached } \\
\text { storage }\end{array}$ \\
\hline Size / Scalability & $100 \mathrm{~s}$ & $1000 \mathrm{~s}$ & $100 \mathrm{~s}$ to $1000 \mathrm{~s}$ \\
\hline $\begin{array}{l}\text { Node Operating } \\
\text { System (OS) }\end{array}$ & $\begin{array}{l}\text { One of the standard } \\
\text { OSs (Linux, } \\
\text { Windows) }\end{array}$ & $\begin{array}{l}\text { Any standard OS } \\
\text { (dominated by Unix) }\end{array}$ & $\begin{array}{l}\text { A hypervisor (VM) on } \\
\text { which multiple OSs } \\
\text { run }\end{array}$ \\
\hline Ownership & Single & Multiple & Single \\
\hline $\begin{array}{l}\text { Interconnection } \\
\text { Network | Speed }\end{array}$ & $\begin{array}{l}\text { Dedicated, } \\
\text { high-end with low } \\
\text { latency and high } \\
\text { bandwidth }\end{array}$ & $\begin{array}{l}\text { Mostly Internet with } \\
\text { high latency and low } \\
\text { bandwidth }\end{array}$ & $\begin{array}{l}\text { Dedicated, high-end } \\
\text { with low latency and } \\
\text { high bandwidth }\end{array}$ \\
\hline Security/Privacy & $\begin{array}{l}\text { Traditional } \\
\text { login/password-bas } \\
\text { ed. } \\
\text { Medium level of } \\
\text { privacy } \\
\text {-depends on user } \\
\text { privileges. }\end{array}$ & $\begin{array}{l}\text { Public/private key par. } \\
\text { Based authentication } \\
\text { and mapping a user to } \\
\text { an account. Limited } \\
\text { support for privacy }\end{array}$ & $\begin{array}{l}\text { Each user/application } \\
\text { is provided with a } \\
\text { virtual machine. } \\
\text { High security/privacy } \\
\text { is guaranteed. Support } \\
\text { for setting per-file } \\
\text { access } \\
\text { list(ACL) control }\end{array}$ \\
\hline Discovery & $\begin{array}{l}\text { Membership } \\
\text { services }\end{array}$ & $\begin{array}{l}\text { Centralised indexing } \\
\text { and decentralised info } \\
\text { services }\end{array}$ & Membership services \\
\hline $\begin{array}{l}\text { Service } \\
\text { Negotiation }\end{array}$ & Limited & Yes, SLA based & Yes, SLA based \\
\hline User Management & Centralised & $\begin{array}{l}\text { Decentralised and also } \\
\text { Virtual Organization } \\
\text { (VO)-based }\end{array}$ & $\begin{array}{l}\text { Centralised or can be } \\
\text { delegated to third } \\
\text { party }\end{array}$ \\
\hline $\begin{array}{l}\text { Resource } \\
\text { Management } \\
\text { Centralized }\end{array}$ & Centralized & Distributed & $\begin{array}{l}\text { Centralized/Distribute } \\
\mathrm{d}\end{array}$ \\
\hline $\begin{array}{l}\text { Allocation/scheduli } \\
\text { ng Centralised }\end{array}$ & Centralized & Decentralised & $\begin{array}{l}\text { Both } \\
\text { centralised/decentralis } \\
\text { ed }\end{array}$ \\
\hline $\begin{array}{l}\text { Standards / Inter- } \\
\text { Operability }\end{array}$ & $\begin{array}{l}\text { Virtual Interface } \\
\text { Architecture } \\
\text { (VIA)-based }\end{array}$ & $\begin{array}{l}\text { Some Open Grid Forum } \\
\text { standards }\end{array}$ & $\begin{array}{l}\text { Web Services (SOAP } \\
\text { and REST) }\end{array}$ \\
\hline
\end{tabular}




\begin{tabular}{|c|c|c|c|}
\hline $\begin{array}{l}\text { Single } \quad \text { System } \\
\text { Image }\end{array}$ & Yes & No & Yes, but optional \\
\hline Capacity & $\begin{array}{l}\text { Stable and } \\
\text { guaranteed }\end{array}$ & Varies, but high & $\begin{array}{l}\text { Provisioned on } \\
\text { demand }\end{array}$ \\
\hline $\begin{array}{l}\text { Failure } \\
\text { Management } \\
\text { (Self-healing) }\end{array}$ & $\begin{array}{l}\text { Limited (often } \\
\text { failed } \\
\text { tasks/applications } \\
\text { are } \\
\text { restarted). }\end{array}$ & $\begin{array}{l}\text { Limited (often failed } \\
\text { tasks/applications are } \\
\text { restarted). }\end{array}$ & $\begin{array}{l}\text { Strong support for } \\
\text { failover and content } \\
\text { replication. VMs } \\
\text { can be easily migrated } \\
\text { from one node to } \\
\text { other. }\end{array}$ \\
\hline Pricing of Services & $\begin{array}{l}\text { Limited, not open } \\
\text { market }\end{array}$ & $\begin{array}{l}\text { Dominated by public } \\
\text { good or privately } \\
\text { assigned }\end{array}$ & $\begin{array}{l}\text { Utility pricing, } \\
\text { discounted for } \\
\text { larger customers }\end{array}$ \\
\hline Internetworking & $\begin{array}{l}\text { Multi-clustering } \\
\text { within an } \\
\text { organization }\end{array}$ & $\begin{array}{l}\text { Limited adoption, but } \\
\text { being explored through } \\
\text { research efforts such as } \\
\text { Gridbus InterGrid }\end{array}$ & $\begin{array}{l}\text { High potential, third } \\
\text { party solution } \\
\text { providers can loosely } \\
\text { tie together services of } \\
\text { different Clouds }\end{array}$ \\
\hline $\begin{array}{l}\text { Application } \\
\text { Drivers }\end{array}$ & $\begin{array}{l}\text { Science, business, } \\
\text { enterprise } \\
\text { computing, data } \\
\text { centers }\end{array}$ & $\begin{array}{l}\text { Collaborative scientific } \\
\text { and high throughput } \\
\text { computing applications }\end{array}$ & $\begin{array}{l}\text { Dynamically } \\
\text { provisioned } \\
\text { legacy and web } \\
\text { applications, } \\
\text { Content delivery }\end{array}$ \\
\hline 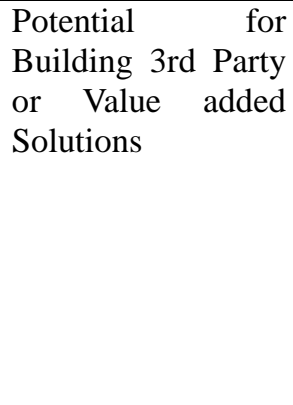 & $\begin{array}{l}\text { Limited due to } \\
\text { rigid architecture }\end{array}$ & $\begin{array}{l}\text { Limited due to strong } \\
\text { orientation for scientific } \\
\text { computing }\end{array}$ & $\begin{array}{l}\text { High potential - can } \\
\text { create new services by } \\
\text { dynamically } \\
\text { provisioning of } \\
\text { compute, storage, and } \\
\text { application services } \\
\text { and offer as their own } \\
\text { isolated or composite } \\
\text { Cloud services to } \\
\text { users }\end{array}$ \\
\hline
\end{tabular}

\section{Architecture of Commercial Cloud System}

Since consumers fulfill their computing needs by Cloud providers, they may require specific QoS to be maintained by their providers in order to meet their objectives and buttress their operations. Cloud providers consider and meet different QoS parameters of each individual consumer as negotiated in specific SLAs. To achieve this, Cloud providers can no longer continue to deploy traditional system-centric resource management architecture that do not provide incentives for them to sa their resources and still regard all service requests to be of equal overriding object. Instead, market-oriented resource management [11] is necessary to regulate the supply and demand of Cloud resources to achieve market equilibrium, providing feedback in terms of economic incentives for both Cloud consumers and providers, and promoting QoS-based resource allocation mechanisms that differentiate service requests 
based on their utility. Additionally, clients can benefit from the "potential" cost reduction of providers, which could lead to a more competitive market and thereby, lower prices.

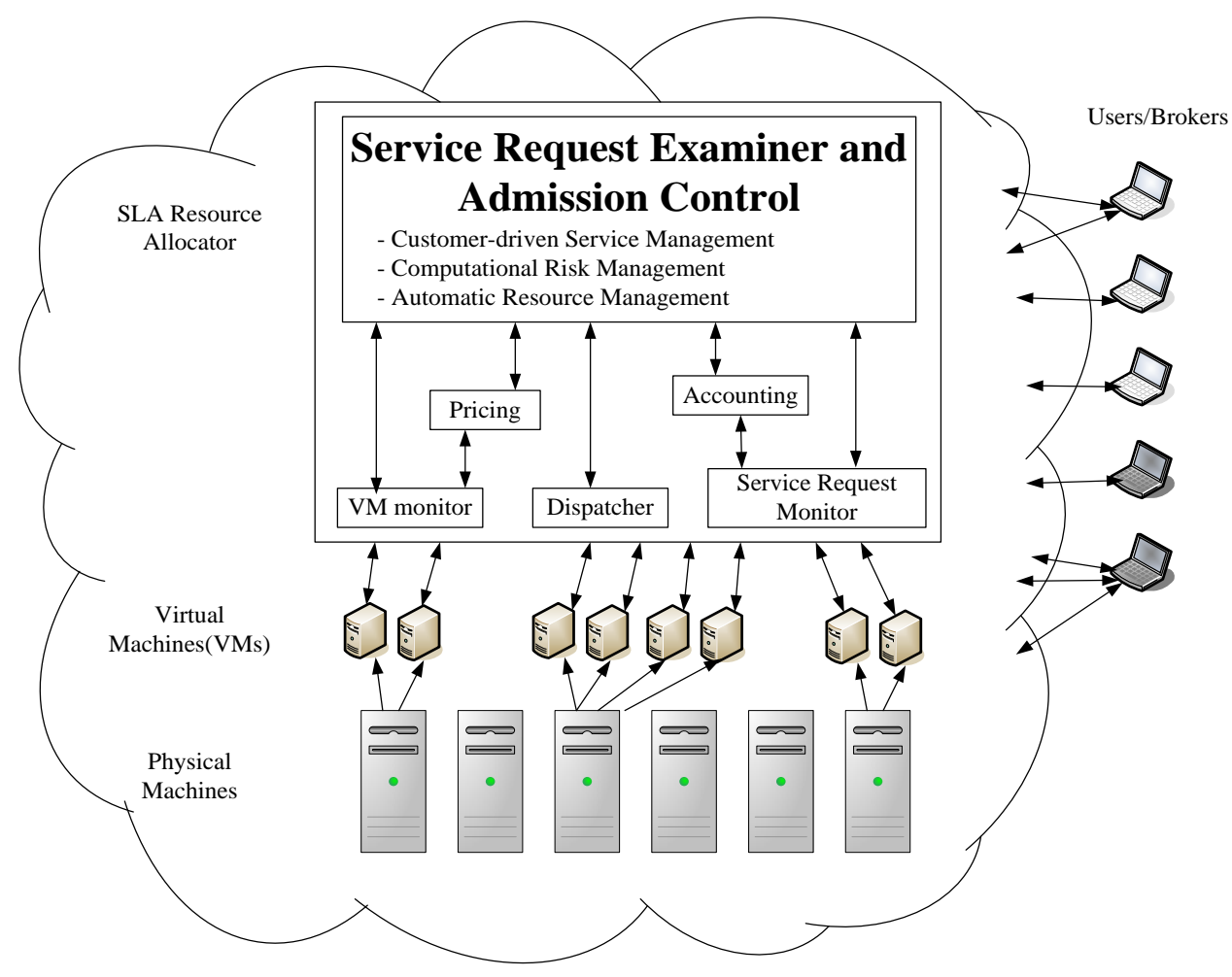

Figure 1. Architecture of Commercial Cloud System [11]

Figure 1 describes the high-level architecture of the market-oriented resource allocation in Clouds and Data Centers. The essential main entities are users, SLA resource allocator, VMs, and physical machines. As for the users or brokers, they can send requests for service from all over the world. Data Center and Cloud will be processed as soon as the requests are available. SLA resource allocator can act as the interface between Data Center (or Cloud) service provider and the external users (or brokers). However, in the SLA resource allocator, some reciprocity of mechanisms are considered to support SLA-oriented resource management, including Servicer Request Examiner and Admission Control, Pricing, Accounting, VM Monitor, Dispatcher and Service Request Monitor [1-2]. Apropos of the VMs, it can be started and ceased by a single machine, meeting accepted service requests. Therefore, VMs can offer the greatest flexibility to configure different separations of resources on the identical machine to various specific requirements of requests. Moreover, multiple VMs can run applications based on different operating system environments on an onefold machine. Besides above-mentioned entities, physical machines are playing an crucial role that the Data Center comprises multiple computing servers that make resources to confront the demands of service.

As for Cloud, as a commercial offering to ensure overriding business operations of corporations, there are crucial QoS parameters that considering in a request of service. Especially the QoS requirements, which cannot be static and can be different over time because of the persistent changes in operating environments. Additionally, Cloud computing has finite support for dynamic negotiation of SLAs between participants and those 
mechanisms for automatic allocation of resources to relative requests.

In the aspect of the commercial offerings of market-oriented Clouds, we put forward the requests of this aspect in accordance with previous excellent research [1-3]. First of all, the commercial offerings should bolster the customer-driven service management on the basis of the requirements and the profiles of customer. Secondly, they should derive appropriate market-based resource management policies which can revolve round with computational risk management and service management of customer, so that, the allocation of resource can be buttressed efficaciously. What's more, the strategies of identifying and managing risks within the implementation of relative applications service requirements and customer needs by computation is also crucial in practical applications. Last but not least, the leverage VM technology to dynamically assign resource also shares in accordance with the requirements of our service.

\section{Economic Efficiency of Using Cloud for Medium-sized Enterprise}

We can suppose that there is a medium-sized school with 1000 student and 200 faculties and staff, with the demands of Web server, FTP server, DNS Server, and Office Automation (OA) system server. In conventional ways, the school would have to purchase at least 4 physical server machines and establish a server room with 24/7 air conditioning and Uninterrupted Power Supply (UPS). The server is supposed be obsoleted in 5 years.

Table 3. Cost of Traditional Server Room in 5 Years

\begin{tabular}{|c|c|c|c|}
\hline & Purchase price & Maintenance Cost/month & Depreciation/month \\
\hline Web Server & $\$ 10,000$ & $\$ 50$ & $\$ 167$ \\
\hline Mail Server & $\$ 10,000$ & $\$ 50$ & $\$ 167$ \\
\hline DNS Server & $\$ 5,000$ & $\$ 50$ & $\$ 83$ \\
\hline OA server & $\$ 5,000$ & $\$ 50$ & $\$ 83$ \\
\hline $\begin{array}{c}\text { Air } \\
\text { conditioner }\end{array}$ & $\$ 10,000$ & $\$ 200$ & - \\
\hline UPS & $\$ 2,000$ & $\$ 50$ & - \\
\hline Total & $\$ 42,000$ & $\$ 450$ & $\$ 700$ \\
\hline
\end{tabular}

By the time the server is obsoleted in 5 years, the total cost of a small traditional server room is hypothetically 27,000 USD.

Table 3. Cost of Using Cloud Service in 5 Years

\begin{tabular}{|c|c|c|c|}
\hline & Purchase price & Rental Cost/month & Depreciation/month \\
\hline Web Server & $\$ 0$ & $\$ 60$ & $\$ 0$ \\
\hline Mail Server & $\$ 0$ & $\$ 60$ & $\$ 0$ \\
\hline DNS Server & $\$ 0$ & $\$ 10$ & $\$ 0$ \\
\hline OA server & $\$ 0$ & $\$ 8$ & $\$ 0$ \\
\hline Air conditioner & $\$ 0$ & $\$ 0$ & - \\
\hline UPS & $\$ 0$ & $\$ 0$ & - \\
\hline Total & $\$ 0$ & $\$ 138$ & $\$ 0$ \\
\hline
\end{tabular}

In five years, the rental cost of cloud server is 8,280 USD, $36 \%$ of traditional server room cost. Furthermore, the cloud service provides various kinds of flexibility and reliability which 
cannot be provided by traditional server room, for instance flexible network bandwidth, Memory, storage space, and disaster recovery capability.

Cloud computing is a novel paradigm delivering services as computing utilities. As Clouds are planned to offer services to external users, providers should be made up for sharing their resources and abilities. In our study, we redefined the concept of cloud computing and proposed architecture for market-oriented allocation of resources within Clouds. Moreover, our study indicates that by using Clouds, the economical efficiency of medium-sized enterprise was proved to be effective

\section{Acknowledgments}

This research is a comprehensive study of the cloud computing, which is chiefly inspired by "A break in the clouds: towards a cloud definition" by L.M. Vaquero [1] and "Cloud computing and emerging IT platforms: Vision, hype, and reality for delivering computing as the 5th utility" by R. Buyya [9]. Our work was developed on the basis of the plenty previous researches and conceptions provided by various references and reports. We appreciate the great previous works provided by relative experts.

\section{References}

[1] L. M. Vaquero, L. Rodero-Merino and J. Caceres, "A break in the clouds: towards a cloud definition", ACM SIGCOMM Computer Communication Review, vol. 39, no. 1, (2008), pp. 50-55.

[2] J. Geelan, "Twenty-one experts define cloud computing”, Cloud Computing Journal, vol. 2, (2009), pp. 1-5.

[3] R. Buyya, C. S. Yeo and S. Venugopal, "Market-oriented cloud computing: Vision, hype, and reality for delivering it services as computing utilities", High Performance Computing and Communications, HPCC'08. 10th IEEE International Conference on. Ieee, (2008), pp. 5-13.

[4] R. Bragg, "Cloud computing: When computers really rule", Tech News World, July 2008. Electronic Magazine, (2009).

[5] E. Knorr and G. Gruman, "What cloud computing really means", InfoWorld, vol. 7, (2008).

[6] P. McFredries, "Technically speaking: The cloud is the computer", Spectrum, IEEE, vol. 45, no. 8, (2008), pp. 20-20.

[7] E. Hand, "Head in the clouds", Nature, (2007), pp. 449: 963.

[8] G. F. Pfister, "In search of clusters", Prentice-Hall, Inc., (1998).

[9] R. Buyya, "High performance cluster computing", New Jersey: F'rentice, (1999).

[10] R. Buyya, C. S. Yeo and S. Venugopal, "Cloud computing and emerging IT platforms: Vision, hype, and reality for delivering computing as the 5th utility", Future Generation computer systems, vol. 25, no. 6, (2009), pp. 599-616.

[11] R. Buyya, D. Abramson and S. Venugopal, "The grid economy", Proceedings of the IEEE, vol. 93, no. 3, (2005), pp. 698-714.

[12] I. Foster, Y. Zhao and I. Raicu, "Cloud computing and grid computing 360-degree compared", Grid Computing Environments Workshop, 2008. GCE'08, IEEE, (2008), pp. 1-10.

[13] D. Nurmi, R. Wolski and C. Grzegorczyk, "The eucalyptus open-source cloud-computing system", Cluster Computing and the Grid, 2009. CCGRID'09. 9th IEEE/ACM International Symposium on. IEEE, (2009), pp. 124-131.

[14] M. D. De Assunção, A. Di Costanzo and R. Buyya, "Evaluating the cost-benefit of using cloud computing to extend the capacity of clusters", Proceedings of the 18th ACM international symposium on High performance distributed computing. ACM, (2009), pp. 141-150.

[15] B. P. Rimal, E. Choi and I. Lumb, "A taxonomy and survey of cloud computing systems", INC,IMS and IDC, 2009. NCM'09. Fifth International Joint Conference on. IEEE, (2009), pp. 44-51.

[16] L. Wang, J. Tao and M. Kunze, "Scientific Cloud Computing: Early Definition and Experience", HPCC, vol. 8, (2008), pp. 825-830.

[17] C. Evangelinos and C. Hill, "Cloud computing for parallel scientific hpc applications: Feasibility of running coupled atmosphere-ocean climate models on amazon's ec2”, ratio, vol. 2, no. 2.40, (2008), pp. 2.34. 


\section{Authors}

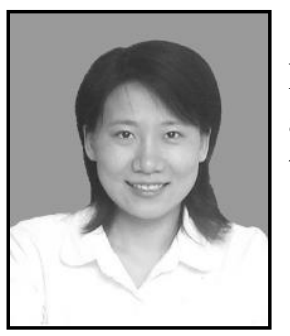

Tao Feng ${ }^{1}$, Tongji University master of software engineering, Professor, senior engineer, deputy, system analyst. With the system analysis ability, familiar with the mainstream web development technologies (ASP, asp.net, JSP, PHP).

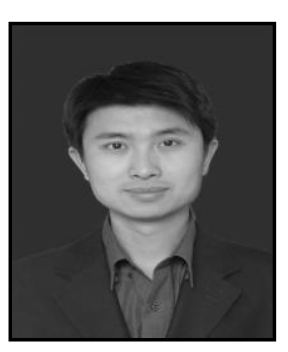

Yun Cheng', Shenyang University of Technology master of management science and Engineering, ERP Manager. 
International Journal of Grid Distribution Computing Vol.7, No.6 (2014) 